\title{
Comprehension of Compound Words in 3-4 Grade School-Aged Children with Poor Reading Comprehension
}

\author{
Ji Sim ${ }^{a}$, Eun-Ju Lee ${ }^{b}$ \\ ${ }^{a}$ Department of Speech and Language Pathology, Graduate School, Dankook University, Yongin, Korea \\ ${ }^{b}$ Department of Special Education, Dankook University, Yongin, Korea
}

Correspondence: Eun-Ju Lee, PhD

Department of Special Education, Dankook

University, 152 Jukjeon-ro, Suji-gu, Yongin 16890,

Korea

Tel: +82-31-8005-3818

Fax: +82-31-8019-7139

E-mail: slplee@dankook.ac.kr

Received: April 6, 2018

Revised: May 28, 2018

Accepted: June 4, 2018

This paper is based on the master's thesis of the first author.

\begin{abstract}
Objectives: Compound words, which occupy a high ratio in school-aged vocabulary, for necessary for semantic understanding of morphemes due to semantic combination. The study investigated the semantic processing characteristics of compound words through dominant/subordinate tasks for children with poor reading comprehension. Methods: The participants were 11 children with poor reading comprehension and 11 typically developing children in the 3rd to 4 th grade of elementary school. The children were asked to judge whether the meaning of the homonym at the end of the phrase was related to the meaning of the homonym used in the compound words presented later through a semantic judgment task. At that time, the target word presented after the phrase was divided into the dominant and the subordinate, and the total number of the correct responses and the responses time were measured for each condition. Results: Children with poor reading comprehension showed significantly lower performance in correct responses and response times according to the dominant and subordinate tasks. Conclusion: Children with poor reading comprehension showed difficulty in understanding and processing the meaning of compound words made up of several morphemes. The study addresses the vocabulary knowledge, word semantic processing speed in relation to semantic processing of compound words in children with poor comprehension.
\end{abstract}

Keywords: Poor reading comprehension, Compound words, Semantic judgment task
학령기는 학업을 수행하는 중요한 시기로 읽기, 쓰기 등 학습을 위한 문어의 어려움은 이 시기에 가장 큰 문제로 부각된다. 읽기는 음독에만 국한되지 않고 문장, 문단으로 이루어진 글 자료를 이해 하여 다양한 교과목을 학습하는 데 큰 영향을 미친다. 읽기를 위해 서는 글자음독(decoding)과 언어이해(linguistic comprehension) 두 가지 요소가 필수적인데(Hoover \& Gough, 1990), 이 두 가지 요 소 중 음독능력은 정상적으로 발달하나 읽기이해에 문제를 보이는 아동을 읽기이해부진(reading comprehension deficit)이라 지칭한 다(Cain \& Oakhill, 2007). 읽기이해를 위해 전제가 되는 음독능력 이 확립되지 않은 읽기 학습 초기에는 읽기이해 문제가 두드러지지 않으나 학년이 올라가면서 음독능력이 안정된 이후 읽기이해의 문 제는 보다 중요하게 다루어진다(Jeong, 2009). 읽기 발달은 단어의
음운적 처리와 의미적 처리를 필요로 하는데, 읽기이해부진아동은 단어일기 능력과 음운적 처리는 정상이나 단어 수준의 의미 처리 가 빈약하다(Nation \& Snowling, 1998). 연구에 의하면 읽기이해부 진아동의 단어 의미 처리 특성을 알아보기 위해 E-Prime을 사용 하여 점화과제, 의미 관련성 판단 과제를 제작하였고, 그 결과 일반 아동에 비해 단어 수준의 의미 처리 과제에서 낮은 수행을 보였다 (Choi \& Hwang, 2010; Ko, Choi, \& Hwang, 2010; Nation \& Snowling, 1999). 본 연구에서는 학령기 읽기이해부진아동을 대상으로 읽기이해 과정 중 단어에 대한 의미 처리 특성을 살펴보고자 한다. 교과목 학습을 위하여 읽기이해의 중요성이 강조되면서 읽기이 해부진아동이 읽기이해에 어려움을 보이는 이유를 알아보고자 많 은 학자들이 읽기능력에 영향을 미치는 관련 변인에 대한 연구들 
을 활발하게 진행하였다. 읽기능력에 영향을 주는 변인으로 음운 인식, 어휘, 읽기유창성, 단기 및 작업기억, 빠른 이름대기, 듣기이해 등을 제시하였고, 특히 어휘는 초등학교 전반에 거쳐 요구되는 기 술로 읽기이해를 예측하는 중요한 변인이라는 연구결과들이 보고 되었다(Cunningham \& Stanovich, 1997; Kim, Yoo, Hwang, Kim, \& Koh, 2010; Ouellette, 2006; Ouellette \& Beers, 2010; Ricketts, Nation, \& Bishop, 2007; Yovanoff, Duesbery, Alonzo, \& Tindal, 2005). 이는 읽기부진아동을 대상으로 실시한 연구에서도 어휘가 읽기이해를 유의하게 예측하는 중요한 변인으로 나타났다(Kim \&

Hwang, 2008; Kim \& Lee, 2010).

학령기에는 읽기를 통해 새로운 어휘를 습득함에 따라 어휘량은 학년이 올라갈수록 크게 성장한다. Anglin (1993)이 학령기 아동의 어휘량을 분석한 결과, 초등학교 1 학년의 표현어휘는 약 2,600 개이 고 초등학교 6학년이 되면 표현어휘가 50,000개에 이르다가 고등학 생이 되면 80,000 개까지 증가한다고 하였다. 어휘능력은 평생 동안 지속적으로 발달하는 능력으로 어휘지식은 듣고 말하기에서 뿐만 아니라 읽고 쓰는 과정에서도 사용되며 읽기이해를 위해서는 우선 적으로 글에 나타난 어휘의 의미를 알아야 한다. Zoh 등(2003)은 글을 이해하는 데 개별 단어 의미가 필수적으로 파악되어야 하며 어휘가 언어 이해의 기본 단위라고 하였다. 어휘지식은 크게 양적 어 휘와 질적 어휘로 나뉘다. 양적 어휘지식은 얼마나 많은 어휘의 의 미를 알고 있는지의 어휘의 양(vocabulary size)과 관련이 있고, 질 적 어휘지식은 그 어휘들을 얼마나 잘 알고 있는지의 어휘의 깊이 (depth of vocabulary)와 관련이 있다(as cited in Schmitt, 2014). 어 휘의 깊이는 동음이의어, 반의어, 상하위적 관계 등 단어들 간의 관 계를 얼마나 잘 인식하는지에 대한 개념과(Park \& Yu, 2009) 음소 적, 형태적, 의미적 특성 등 어휘의 다양한 특성 및 빈도를 포함한다 (Qian \& Schedl, 2004). 읽기이해부진아동을 대상으로 한 어휘지식 과 관련된 선행연구에서는 읽기이해부진아동이 단어 간의 의미관 계를 유추하는 데 어려움을 보이고(Jeong, 2009), 양적 어휘와 질적 어휘에서 일반아동과 유의한 차이를 보이는 것으로 보고되었다 (Baker, Simmons, \& Kameenui, 1998; Kim, 2013; Nation \& Snowling, 1998). 이러한 결과는 읽기이해부진아동이 단어 간 의미관계를 이해하여 처리하는 데 어려움을 보이고, 어휘지식에서 양적 증가와 질적 심화에 어려움을 보임을 시사한다.

성공적인 읽기이해에 어휘지식이 중요하나 읽기이해부진아동이 어휘지식에서 특히 어려움을 보인다고 할 때, 읽기이해부진아동은 학령기에 본격적으로 학습이 이루어지는 합성어(compound words) 의미 처리 과정에서 어려움을 겪을 수 있다. 합성어는 여러 개의 형 태소로 이루어진 복합어로 어근과 어근의 결합으로 이루어진다. 합
성어는 명사, 동사, 형용사 등이 결합하여 새로운 낱말을 만들어 내 는데, 이 중 명사+명사의 결합은 합성어의 가장 흔한 구성 방식이며 (Kang, 2010) 생산성이 매우 높은 형태적 구조이다(Han et al., 2010). $\mathrm{Kim}$ (2000)은 명사+명사가 결합하는 경우 각 구성요소의 의미가 대등적으로 결합하여 복합적인 의미를 만들거나 한 구성요소 의미 가 다른 구성요소 의미를 수식, 한정함으로써 복합적인 의미를 만 든다고 하였다. 두 개 이상의 형태소 결합으로 이루어진 합성어는 단어의 구조인 형태적 특성을 이해하는 것도 필요하나 최소의 의미 를 지닌 형태소들의 의미적인 결합이므로 형태소의 의미를 이해하 는 것이 필요하다. 초등학교 3,4 학년 국어 교과서의 어휘 조사 연구 에서 어휘의 구성별 분포 결과에 따르면 단일어 $30.07 \%$, 합성어 $41.09 \%$, 파생어 $24.84 \%$ 로 합성어가 높은 비율을 차지한다고 하였 고(as cited in Kwak, 2004), Roh (2014)가 2002년부터 2010년까지 의 신어자료집을 바탕으로 교육용 신어를 분석한 결과에서도 단일 어(14.7\%)와 파생어(24.5\%)에 비해 합성어(41.8\%)가 높은 비율을 차지한다고 하였다. 이와 같은 조사 결과에 따라 학령기 아동이 합 성어 의미를 처리하는 능력은 글을 읽고 의미를 이해하는 측면에 서 큰 비중을 차지한다고 예상해볼 수 있다. 학령기에는 합성어가 높은 비율을 차지하고 있으나 읽기이해부진아동의 합성어 의미 처 리에 대한 연구는 부족한 실정이다. 따라서 본 연구에서는 읽기이 해부진아동의 읽기이해에 대한 어려움을 이해하기 위해 읽기이해 에 필요한 어휘 영역에 대한 연구를 하고자 하였고, 그 중 합성어에 대한 의미 처리 과정을 살펴보고자 하였다.

한편, 동음이의어(homonym)는 동일한 철자와 발음을 가진 낱 말이 두 가지 이상의 의미를 갖는 것으로 예를 들면, '눈'은 '신체 눈' 과 '날씨 눈'의 서로 관련이 없는 두 가지의 뜻을 지닌다. 이러한 동 음이의어가 합성어나 파생어와 같은 복합어에서는 같은 어근이나 접사를 허용하지 않는데, 예를 들어 열매 ‘밤’은 어근 ‘나무’와 결합 하여 ‘밤나무로 바꽈 쓸 수 있으나 저녁 ‘밤’은 그렇지 않다는 것이 다(Hwang, 2016). 또한, 두 가지 이상의 의미를 가진 동음이의어는 그 의미의 친숙도가 똑같지 않는데, 이때 자주 쓰이는 의미를 '우세', 상대적으로 덜 쓰이는 의미를 ‘열세’라고 하며(Lee \& Lee, 2007) 대 부분 우세한 의미가 먼저 선택되고 열세한 의미가 늦게 선택된다고 한다(Lee, 2012). 이를 참고하여 본 연구에서는 동음이의어가 포함 된 합성어를 의미 관련성 판단 과제에 사용함으로써 합성어에서 동음이의어의 의미 친숙도에 따른 처리 과정을 보고자 하였다. 판 단 과제는 정확도와 함께 의미를 처리하기까지의 반응시간 측정이 가능하여 의미 친숙도에 따른 수행 결과에서 어떠한 경향을 보이 는지, 처리 속도에서 집단과 조건에 따른 차이가 있는지 비교가 가 능하다. 읽기이해부진아동의 경우 정오 판단 수행에서는 또래 일반 
아동과 비슷한 수준을 보이기도 하나 반응하는 속도에서 차이를 보인다는 선행연구 결과가 있고(Kim, Hwang, \& Choi, 2013), 우세 의미와 열세의미가 순차적으로 처리된다는 것을 고려하면 의미를 처리하는 과정에서 정반응수와 함께 반응시간을 보는 것이 중요할 것이다. 이에 따라 의미를 처리하는 데 판단 과제를 사용하여 정확 도와 처리시간을 측정하였다.

앞의 내용을 토대로, 본 연구에서는 읽기이해부진아동이 합성어 의미를 처리하는 과정에서 합성어의 의미적인 측면에서 나타나는 특성을 살펴보았다. 이를 위해 우세의미와 열세의미 조건으로 나누 어 합성어 의미 관련성 판단 과제를 제작하였고 읽기이해부진아동 이 일반아동과 정확도와처리속도에서차이가 있는지를 비교하였다.

\section{연구방법}

\section{연구대상}

본 연구의 대상은 수도권 내 초등학교에 재학 중인 3-4학년 읽기 이해부진아동 11 명(3학년 7명, 4학년 4명), 일반아동 11명(3학년 7 명, 4 학년 4명)으로 총 22 명이었다. 읽기이해부진아동 선정기준은 다음과 같다. (1) 지역아동센터의 담당자에 의해 읽기이해에 어려 움이 있다고 보고된 아동 중에서, (2) 기초학력검사(Korea Institute for Special Education-Basic Academic Achievement Test, KISEBAAT; Park, Kim, Song, Jung, \& Jung, 2008) 결과, 음독검사에서 $25 \%$ ile 이상, 짧은글 이해검사에서 $25 \%$ ile 이하이며, (3) 한국어판 웩슬러 아동 지능검사 3판(Korean Wechsler Intelligence Scale for Children-III, K-WISC-III; Kwak, Park, \& Kim, 2001) 결과, 동작성 지능이 85 이상인, (4) 감각적, 정서적, 사회심리적, 신경학적 문제가 없는 아동으로 선정하였다. 일반아동 선정기준은 다음과 같다. (1) 지역아동센터의 담당자에 의해 읽기이해에 어려움이 없다고 보고 된 아동 중에서, (2) KISE-BAAT (Park et al., 2008) 결과, 음독검사 와 짧은글 이해 검사가 $25 \%$ ile 이상이고, (3) K-WISC-III (Kwak et al., 2001) 결과, 동작성 지능이 85 이상인, (4) 감각적, 정서적, 사회심 리적, 신경학적 문제가 없는 아동으로 선정하였다.

연구대상에 대한 정보는 Table 1과 같다.

\section{연구도구}

본 연구에서는 합성어 의미 처리 특성을 알아보기 위하여 의미 관련성 판단 과제를 사용하였다. 이 과제는 관형구를 읽고 관형구 의 마지막에 위치한 동음이의어의 의미가 표적단어(target word)인 합성어에 포함된 동음이의어의 의미와 관련이 있는지 없는지 판단 하는 것이다. 본 연구에서 우세의미 조건과 열세의미 조건에서 제
Table 1. Participants' characteristics

\begin{tabular}{lccc}
\hline & $\begin{array}{c}\text { Poor compre- } \\
\text { henders }(\mathrm{N}=11)\end{array}$ & $\begin{array}{c}\text { Normal readers } \\
(\mathrm{N}=11)\end{array}$ & $t$ \\
\hline Age $(\mathrm{mo})$ & $114.81(6.56)$ & $118.81(7.16)$ & 1.365 \\
Performance $10^{\mathrm{a}}$ & $102.18(11.19)$ & $109.00(12.67)$ & 1.337 \\
Decoding $^{\mathrm{b}}$ \%ile) & $95.63(8.41)$ & $98.00(4.44)$ & .823 \\
Text comprehension $^{\mathrm{b}}$ (\%ile) & $14.09(5.30)$ & $87.00(13.27)$ & $16.918^{* * *}$ \\
\hline
\end{tabular}

Values are presented as mean (SD).

aKorean-Wechsler Intelligence Scale for Children-III (K-WISC-III; Kwak, Park, \& Kim, 2001).

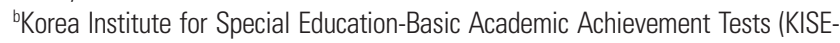
BAAT; Park, Kim, Song, Jung, \& Jung, 2008).

${ }^{* * *} p<.001$.

시된 표적단어인 합성어는 항상 의미상 관련이 있으므로 “예”가 정 반응이다. “아니오” 반응 기회를 제공하기 위한 채움(filler) 조건은 항상 의미상 관련이 없으며 단일어로 구성되었다. 실험 과제는 연 습 문항 8 개, 본 문항 54 개로 제작하였다. 본 문항 54 개는 우세의미, 열세의미의 2 가지 조건에 대하여 각각 18 개씩 36 개와 채움 조건 18 개로 구성하였다. 모든 문항은 관형구와 표적단어로 구성하였고, 실험에 사용되는 관형구의 통사적 길이 및 문장의 복잡성을 통제 하기 위하여 3어절이면서 어절당 음절수는 1-4음절, 전체 음절수 는 5-9음절로 조절하였다. 표적단어로 제시되는 합성어에서 동음 이의어는 어근의 앞 또는 뒤에 위치하며 위치 영향을 배제하기 위 하여 우세열세 짝을 이루는 문항에서 동음이의어는 같은 위치에 놓이도록 통제하였다. 전체 문항의 순서는 무작위로 한 뒤, 동일 조 건이 3 회 이상, 의미 관련성 판단에서 동일 반응이 3 회 이상 반복되 지 않도록 조정하였다.

연구에 사용된 동음이의어는 선행연구(Jang, Jeong, \& Hwang, 2014; Kang, Hwang, \& Lim, 2013; Lee \& Lee, 2006; Park, 2015; Shin \& Lee, 2016)의 동음이의어 목록과 $\operatorname{Kim}(2003)$ 의 등급별 국어교육 용 어휘를 참고하여 기초어휘 등급인 1 등급에서 정규교육 개시 등 급인 2등급 이내이며 1-2음절인 명사로 선정하였다. 합성어, 단일어 는 국립국어원 표준국어대사전을 참고하여 초등학교 저학년 아동 이 이해할 수 있다고 판단되는 수준에서 합성어는 동음이의어가 포함된 2-4음절, 단일어는 2-3음절의 명사로 선정하였다. 선정된 동 음이의어, 합성어, 단일어 어휘는 초등학교 3-4학년 아동에게 적합 한지 알아보기 위해 초등학생의 어휘능력 수준을 잘 파악하고 있 는 교직생활 15 년 이상인 교사 3 명에게 타당도를 검증받았다. 타당 도 검증은 매우 어려움, 약간 어려움, 적절함, 약간 쉬움, 매우 쉬움 의 Likert 5 점 척도로 이루어졌고, 그 결과 교사 2 명 이상이 어려움 으로 평정한 어휘는 수정하였다.

동음이의어의 우세의미와 열세의미 분류는 초등학교 3 학년 20 
명, 4 학년 20 명을 대상으로 설문지를 제시하여 동음이의어를 읽고 단어에 대해 떠오르는 의미나 단어가 쓰이는 예시를 모두 쓰도록 하였다. 설문지의 응답에서 아동이 처음으로 쓴 의미를 계산하여 2 가지 의미 중 높은 비율로 반응한 의미를 상대적으로 우세의미로, 낮은 비율로 반응한 의미를 상대적으로 열세의미로 분류하였다. 합성어는 동음이의어의 앞 또는 뒤에 어근이 결합된 '명사+명사' 형태로 '동음이의어+어근' '어근+동음이의어'로 구성하였다. 합성 어는 동음이의어가 없는 한 가지 의미만을 가지며 합성어가 만들어 질 때 어근의 형태에 변화가 없는 것으로 구성하였다. 이같은 과정 을 거쳐 본 연구에서 사용된 동음이의어, 합성어, 단일어 어휘를 수 정 및 보완하여 최종적으로 동음이의어 18 개, 합성어 36 개, 단일어 18 개를 선정하였다.

본 실험에 사용된 관형구와 표적단어 예시는 Appendix 1과 같다.

\section{연구절차}

연구절차를 파워포인트로 제작하여 연구자가 아동과 화면을 함 께 보면서 설명을 제공하였다. 아동이 충분히 이해한 것으로 확인 되면 연습 문항 8 개(실험 조건 4개, 채움 조건 4개)를 실시하였고, 아동이 과제 수행에 어려움을 보이거나 키보드 및 마우스 조작이 미숙한 경우에는 재설명 후 연습과제를 1 회 더 실시하고 본 과제를 진행하였다. 아동은 화면을 보면서 키보드와 마우스를 조작하여 과제를 수행하였고, 이때 마우스를 가능한 한 정확하고 빠르게 누 르도록주의사항을 설명해주었다.

실험 과제는 노트북(LG15U47)으로 E-Prime을 사용하여 제작 하였다. 아동에게 제시되는 문항은 하얀 바탕에 18 point의 검정색 Courier New체로 중앙에 나타났다. 지시문이 나타나면 아동이 SPACE BAR를 눌러 과제를 시작하게 하였고, 시선을 모니터 중앙 에 고정하도록 응시점(+) 표시가 $500 \mathrm{~ms}$ 나타났다가 자동적으로 사라진 후 관형구가 제시되었다. 아동이 읽자마자 왼손으로 SPACE $\mathrm{BAR}$ 를 누르면 표적단어가 나타나는데, 이때 관형구의 마지막 단어 의 의미가 표적단어와 관련 있는 의미이면 마우스 왼쪽 ‘예’ 반응을 누르고 관련이 없는 의미라고 판단하면 마우스 오른쪽 '아니오' 반 응을 누르게 하였다. 관형구가 제시된 후 $5,000 \mathrm{~ms}$ 가 경과되면 반 응을 하지 않더라도 자동적으로 사라지고 표적단어가 제시되도록 하였다(Figure 1).

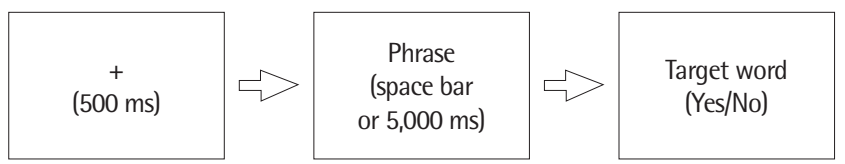

Figure 1. Process of semantic judgment task.

\section{자료 분석 및 처리}

본 연구는 '예'라고 판단한 문항에 대해 우세 조건과 열세 조건 각각에 따른 정반응수와 정반응에 대한 반응시간을 측정하여 분 석하였고, ‘아니오'라고 판단한 문항은 채움 조건으로 분석에 포함 하지 않았다.

읽기이해부진아동과 일반아동이 우세와 열세 의미에 따른 차이 를 보이는지 알아보기 위해 집단(2) $\times$ 조건(2)의 이원분산분석(twoway ANOVA)을 실시하였고 조건은 반복측정(repeated measure) 하였다. 수집된 자료는 SPSS version 21.0 for Window를 사용하여 분석하였다.

\section{연구결과}

읽기이해부진아동과 일반아동의 우세/열세의미 조건에 따른 정 반응수의 기술통계는 Table 2에 제시하였다. 조건별 정반응수 차이 를 알아보기 위한 이원분산분석 결과, 집단 간주효과 $\left(F_{(1,20)}=12.048\right.$, $p<.01)$, 조건 간 주효과 $\left(F_{(1,20)}=5.294, p<.05\right)$ 는 유의하였으나, 집 단과 조건 간 상호작용 효과 $\left(F_{(1,20)}=.588, p=.452\right)$ 는 유의하지 않았 다. 이와 같은 결과로 보아 읽기이해부진아동이 일반아동에 비해 우세/열세의미 조건에서 모두 저조한 수행을 보였음을 알 수 있다.

의미 관련성 판단 과제에서 읽기이해부진아동과 일반아동이 우 세/열세의미 조건에 따른 반응시간의 기술통계는 Table 3에 제시하 였다. 조건별 반응시간 차이를 알아보기 위한 이원분산분석 결과, 집단 간 주효과 $\left(F_{(1,20)}=8.267, p<.01\right)$, 조건 간 주효과 $\left(F_{(1,20)}=10.098\right.$, $p<.01)$ 는 유의하였으나, 집단과 조건 간 상호작용 효과 $\left(F_{(1,20)}=.799\right.$, $p=.382)$ 는 유의하지 않았다. 이는 읽기이해부진아동이 일반아동 에 비해 우세/열세의미 조건에서 모두 의미판단시간이 더 소요되

Table 2. Descriptive data of correct response score by word meaning condition

\begin{tabular}{lcc}
\hline & $\begin{array}{c}\text { Poor comprehenders } \\
(\mathrm{N}=11)\end{array}$ & $\begin{array}{c}\text { Normal readers } \\
(\mathrm{N}=11)\end{array}$ \\
\hline Dominant meaning $^{\mathrm{a}}$ & $13.09(2.38)$ & $15.54(1.86)$ \\
Subordinate meaning $^{\mathrm{a}}$ & $12.00(2.00)$ & $15.00(1.78)$ \\
\hline
\end{tabular}

Values are presented as mean (SD).

${ }^{a}$ Total score $=18$ points.

Table 3. Descriptive data of response time (ms) by word meaning condition

\begin{tabular}{lcc}
\hline & $\begin{array}{c}\text { Poor comprehenders } \\
(\mathrm{N}=11)\end{array}$ & $\begin{array}{c}\text { Normal readers } \\
(\mathrm{N}=11)\end{array}$ \\
\hline Dominant meaning & $1,373.69(195.15)$ & $1,066.84(240.32)$ \\
Subordinate meaning & $1,530.44(353.84)$ & $1,154.76(348.53)$ \\
\hline
\end{tabular}

Values are presented as mean (SD). 
었음을 의미한다.

\section{논의 및 결론}

본 연구는 읽기이해부진아동의 합성어 의미 처리 특성을 살펴보 기 위해, 동음이의어의 우세/열세의미 조건에 따른 합성어 의미 관 련성 판단의 정반응수와 반응시간을 측정하여 비교하였다.

합성어 의미 관련성 판단 정반응수를 분석한 결과, 읽기이해부진 아동 집단이 일반아동 집단에 비해 낮은 정반응 점수를 보였다. 또 한, 두 집단 모두 우세의미보다 열세의미에서 낮은 수행을 보였다. 이러한 결과는 읽기이해부진아동이 일반아동보다 합성어 의미 관 련성 판단 과제에 대한 수행에서 어려움을 겪음을 시사하며, 여러 선행연구에서 언급한 바와 같이 두 집단 간 어휘지식의 차이에서 비롯된 것일 수 있다. 읽기이해부진아동을 대상으로 어휘지식과 관 련된 연구에서 읽기이해부진아동이 양적어휘와 질적어휘에서 일 반아동에 비해 부족한 것으로 나타난 결과를 뒷받침한다(Baker,

Simmons, \& Kameenui, 1998; Kim, 2013; Nation \& Snowling, 1998). 읽기이해부진아동은 일반아동에 비해 단어 간의 의미관계를 인식 하고 파악하는 능력이 취약하다. 이러한 어휘지식의 부족이 동음이 의어의 의미와 합성어에 포함된 동음이의어의 의미 간의 관계를 파 악하여 처리하는 능력에 영향을 주어 저조한 수행을 나타냈다고 볼 수 있다. 상당수의 어휘가 여러 개의 형태소로 이루어진 다형태 소 단어이고(Zoh et al., 2003), 특히 합성어는 초등학교 3학년 시기 부터 교과내용을 통해 의도적으로 학습한다고 할 때 어휘의 양적, 질적 측면에서 합성어가 큰 비중을 차지한다고 예상해 볼수 있다.

두 집단 모두 우세의미보다 열세의미에서 낮은 수행을 보였다는 결과는 읽기이해부진아동을 대상으로 동음이의어 이해 능력을 살 펴본 Kang 등(2013)의 연구결과와 비슷한 패턴을 보인다. 이러한 경향은 읽기이해부진아동이 열세의미뿐 아니라 우세의미에서도 일반아동에 비해 어려움을 보인다는 것을 나타낸다.

한편으로 본 연구결과는 형태적으로 복잡한 합성어에 대한 의미 관련성 판단 과제를 수행하는 데 있어서 단순히 합성어의 의미를 이해하고 처리하는 능력의 차이뿐 아니라 단어의 구조를 인식하고 의도적으로 조작할 수 있는 능력인 형태소인식능력의 차이로 확장 하여 생각해 볼 수 있다. 형태소인식능력은 초등학교 저학년부터 고학년까지 읽기능력 발달에 지속적으로 기여하여(Roman, Kirby, Parrila, Wade-Woolley, \& Deacon, 2009) 국외의 경우 형태소인식 능력에 관한 연구가 활발하게 진행되어 왔다. 형태소인식능력은 다 형태소 단어를 이해하는 데 중요한 역할을 함으로써 모르는 단어 에 대한 의미 유추를 가능하게 하고(Apel, Diehm, \& Apel, 2013),
나아가 단어 수준에서 요구가 줄어듦에 따라 텍스트 수준에서 이 해를 촉진시켜 효율적인 읽기이해를 돕는다(Kirby et al., 2012). Kim 과 Jeong (2015), Park, Cho와 Yu (2013), Kwak (2016)의 연구에서 읽기장애아동이 일반아동에 비해 형태소인식능력이 유의하게 낮 았다. 형태소인식능력을 합성어 및 파생어 유형에 따라 살펴본 Kim 과 Jeong (2015) 연구결과, 초등학교 저학년 읽기학습부진아동과 일반아동 집단 모두 합성어 과제보다 파생어 과제에서 수행이 저조 하였고 읽기학습부진아동이 두 가지 과제 유형에서 모두 일반아동 에 비해 유의하게 낮은 수행을 보였다. 학령기 아동의 어휘에서 합 성어의 비율이 높다는 것과 읽기학습부진아동이 파생어뿐 아니라 상대적으로 조작의 어려움이 적은 합성어 과제에서도 저조한 수행 을 보였다는 결과를 고려하면, 읽기학습부진아동은 파생어뿐 아니 라 합성어 어휘 처리 부담으로 읽기이해에서 어려움이 더욱 가중될 수 있다는 것을 예측해 볼 수 있다. 또한, 과제가 다르기는 하나 본 연구에서 학년이 더 높은 초등학교 3-4학년 읽기이해부진아동을 대상으로 합성어 의미 처리 능력을 살펴보았을 때 여전히 어려움을 보이는 것으로 보아 초등학교 저학년에서 합성어의 의미를 이해하 고 처리하는 능력에 대한 어려움이 학년이 올라가서도 지속적으로 영향을 줄수 있음을 시사한다.

반응시간에 대한 결과에서는 읽기이해부진아동 집단이 일반아 동 집단에 비해 느린 반응시간을 보였다. 두 집단 모두 우세의미보 다 열세의미에서 반응시간이 더 길었다. 이러한 결과는 읽기이해부 진아동이 관형구의 마지막 어절의 동음이의어와 합성어 내에 포함 된 동음이의어 간에 의미적으로 관련이 있는지 비교하여 판단하 는 데 있어 어려움을 겪었다고 볼 수 있고, 두 집단이 열세의미를 판 단하는 데 있어 더 오래 걸렸다는 것으로 해석할 수 있다.

이러한 결과는 과제가 다르나 읽기이해부진아동을 대상으로 의 미 처리 특성을 살펴본 Choi와 Hwang (2010) 연구에서 읽기이해 부진아동이 일반아동에 비해 단어의미처리속도가 느리다는 결과 와 일치한다. 연구자들은 이 결과를 읽기이해부진아동이 단어의미 처리과정에서 심성어휘집 내에 연결된 의미들 간의 낮은 활성화 강 도로 인하여 반응시간이 늦어졌음을 설명한다. 이와 같이 본 연구 에서도 읽기이해부진아동이 의미와 관련성이 있는 단어를 처리할 때 일반아동에 비해 많은 어려움을 겪는다고 볼 수 있고, 의미 정보 에 대한 활성화 강도가 낮아 오래 걸린 것으로 해석해볼 수 있다. 본 연구에서는 단일어가 아닌 합성어를 사용하였으므로 다형태소로 이루어진 합성어에서 의미를 처리하는 데 더 많은 어려움과 시간 소요가 있었을 것이라고 예상해볼 수 있다. 또한, 두 집단이 우세의 미에 비해 열세의미를 판단하는 데 더 오래 걸렸다는 것은 읽기이 해부진아동도 일반아동과 마찬가지로 단어의 의미적 정보에 대한 
활성화가 이루어지기는 하나 이를 처리하는 속도에서 일반아동과 비교하여 유의하게 느리다는 것을 시사한다.

본 연구는 읽기이해부진아동의 합성어 의미 처리 특성을 의미 관련성 판단 과제를 통해 살펴보았다. 위의 결과를 종합해보면, 읽 기이해부진아동은 복잡한 다형태소로 이루어진 합성어의 의미를 이해하고 처리하는 능력에서 어려움을 보였다. 따라서 읽기이해부 진아동 중재 시 읽기이해를 위해 중요한 변인인 어휘를 포함할 때 학령기에 높은 비율을 차지하는 합성어를 포함해야 하고, 형태소 간의 의미적 결합에 대한 이해와 어휘 습득에서 우세의미와 열세 의미 등을 고려한 다양한 전략을 사용할 수 있도록 지도하는 것이 필요할 것이라 생각된다.

연구의 결과를 해석함에 있어서 제한점과 후속연구를 위한 제언 은 다음과 같다. 첫째, 초등학교 3 학년과 4 학년의 대상자 수가 균등 하지 않았고, 연구결과를 일반화하기에는 대상자의 수가 제한적이 었다. 추후 연구에서는 대상자 수를 균등하게 조절하고 대상자 수 를 확보하는 것이 필요할 것이다. 둘째, 어휘의 양적인 측면에서 아 동들 간의 어휘량의 차이가 본 과제 수행에 영향을 미쳤을 수 있다. 추후 연구에서는 아동의 어휘력검사를 실시하여 어휘량에 따라 과 제 수행에 차이가 있는지 살펴보는 것이 필요할 것이다. 셋째, 복합 어인 합성어, 파생어 중 합성어에 제한하여 의미 처리 특성을 살펴 보았다. 학령기 어휘에서 단일어보다 복합어가 차지하는 비율이 높 고, 합성어와 달리 파생어는 접사와 어근으로 구성된다. 이에 읽기 이해부진아동의 파생어 의미 처리 능력을 살펴보고 이를 비교하여 분석해본다면 복합어에 대한 의미 처리 특성을 통합적으로 살펴보 는 데 도움이 될 것으로 예상된다.

\section{REFERENCES}

Anglin, J. M. (1993). Vocabulary development: a morphological analysis. Monographs of the Society for Research in Child Development, 58, 1-186.

Apel, K., Diehm, E., \& Apel, L. (2013). Using multiple measures of morphological awareness to assess its relation to reading. Topics in Language Disorders, 33, 42-56.

Baker, S. K., Simmons, D. C., \& Kameenui, E. J. (1998). Vocabulary acquisition: research bases. In D. C. Simmons \& E. J. Kameenui (Eds.), What reading research tells us about children with diverse learning needs (pp. 183-217). Mahwah, NJ: Erlbaum.

Cain, K., \& Oakhill, J. (2007). Reading comprehension difficulties: correlates, causes, and consequences. In K. Cain \& J. Oakhill (Eds.), Children's comprehension problems in oral and written language: a cognitive perspective (pp. 41-75). New York, NY: The Guilford Press.

Choi, K. S., \& Hwang, M. A. (2010). Semantic processing in children with poor reading comprehension: semantic priming effect during word reading. Korean Journal of Communication \& Disorders, 15, 168-176.

Cunningham, A. E., \& Stanovich, K. E. (1997). Early reading acquisition and its relation to reading experience and ability ten years later. Developmental Psychology, 33, 934-945.

Han, J. Y., Park, J. Y., Hyun, Y. H., Kwon, S. H., Park, G. Y., Lee, S. U., \& Kim, H. K. (2010). A study of Korean vocabulary education. Paju: Thaehaksa.

Hoover, W. A., \& Gough, P. B. (1990). The simple view of reading. Reading and Writing, 2, 127-160.

Hwang, M. H. (2016). A study on the status of homonymy teaching and its alternatives. The Education of Korean Language, 60, 319-342.

Jang, J. Y., Jeong, M. R., \& Hwang, M. A. (2014). Comprehending and defining homonyms in school-aged children from multicultural families. Communication Sciences and Disorders, 19, 71-79.

Jeong, M. R. (2009). Verbal analogical reasoning skills in poor comprehenders. Korean Journal of Communication \& Disorders, 14, 275-287.

Kang, B. M. (2010). Language (3rd ed.). Seoul: Hankookmunhwasa.

Kang, H. J., Hwang, M., \& Lim, J. A. (2013). The comprehension of homonym in children with poor comprehension skills. The Korea Journal of Learning Disabilities, 10, 161-176.

Kim, A. H. (2013). A comparison of elementary students with reading disabilities to students without disabilities on vocabulary performance and error patterns. The Korea Journal of Learning Disabilities, 10, 51-67.

Kim, A. H., \& Hwang, M. (2008). Prediction of reading skills in upper elementary students. Korean Journal of Communication Disorders, 13, 1-25.

Kim, A. H., Yoo, H. S., Hwang, M., Kim, U. J., \& Koh, S. R. (2010). Prediction of reading comprehension in elementary school. Korean Journal of Communication Disorders, 15, 357-380.

Kim, B. J., Hwang, M., \& Choi, K. S. (2013). Word processing of children with poor reading comprehension during an on-line verbal analogy task. Communication Sciences and Disorders, 18, 269-276.

Kim, D. I., \& Lee, I. H. (2010). The relationship between linguistic component knowledge and reading comprehension for low achieving elementary students. The Korea Journal of Learning Disabilities, 7, 27-45.

Kim, I. B. (2000). A study of compounds words in Korean. Seoul: Youkrack.

Kim, K. H. (2003). Vocabularies for different levels of Korean education. Seoul: Pakijung.

Kim, S. H., \& Jung, K. H. (2015). Morphological awareness and reading abili- 
ties for early elementary school students with poor reading skill. Journal of Speech \& Hearing Disorders, 24, 35-47.

Kirby, J. R., Deacon, S. H., Bowers, P. N., Izenberg, L., Wade-Woolley, L., \& Parrila, R. (2012). Children's morphological awareness and reading ability. Reading and Writing, 25, 389-410.

Ko, S. H., Choi, K. S., \& Hwang, M. (2010). Comprehension of ambiguous words in children with poor reading comprehension. Korean Journal of Communication Disorders, 15, 348-356.

Kwak, A. R. (2016). Morphological awareness and implicit learning ability of children with reading disabilities and typical development (Master's thesis). Ewha Womans University, Seoul, Korea.

Kwak, J. Y. (2004). An analysis of vocabulary in elementary school Korean text. The Korean Language and Literature, 32, 1-28.

Kwak, K. C., Park, H. W., \& Kim, C. T. (2001). Korean Wechsler intelligence scale for children-III (K-WISC-III). Seoul: Seoul Special Education Publishing Co.

Lee, H. R. (2012). Definitional category analysis of ambiguous words in Korean children with autism spectrum disorders. Journal of the Korean Association for Persons with Autism, 12, 21-36.

Lee, S. B., \& Lee, H. R. (2006). Lexical ambiguity comprehension of Korean children with specific language impairments. Korean Journal of Communication Disorders, 11, 14-29.

Lee, S. B., \& Lee, H. R. (2007). Definitional category analysis of ambiguous words in children with specific language impairment. Journal of Speech \& Hearing Disorders, 16, 1-18.

Nation, K., \& Snowling, M. J. (1998). Semantic processing and the development of word-recognition skills: evidence from children with reading comprehension difficulties. Journal of Memory and Language, 39, 85-101.

Nation, K., \& Snowling, M. J. (1999). Developmental differences in sensitivity to semantic relations among good and poor comprehenders: evidence from semantic priming. Cognition, 70, B1-B13.

Ouellette, G. (2006). What's meaning got to do with it: the role of vocabulary in word reading and reading comprehension. Journal of Educational Psychology, 98, 554-566.

Ouellette, G., \& Beers, A. (2010). A not-so-simple view of reading: how oral vocabulary and visual-word recognition complicate the story. Reading and
Writing, 23, 189-208.

Park, G., Kim, G., Song, Y., Jung, D., \& Jung, I. (2008). Korea Institute for Special Education-Basic Academic Achievement Test (KISE-BAAT). Ansan; Korea Institute for Special Education.

Park, S. G., Cho, J. R., \& Yu, Y. M. (2013). A predictor study on the literacy of reading underachievers. Special Education Research, 12, 155-180.

Park, S. Y. (2015). The Comprehension of homonym in normal children and children with poor reading comprehension (Master's thesis). Dankook University, Yongin, Korea.

Park, Y. M., \& Yu, J. B. (2009). Vocabulary teaching and learning through pattern poetry writing. Journal of Research in Curriculum \& Instruction, 13, 299-321.

Qian, D. D., \& Schedl, M. (2004). Evaluation of an in-depth vocabulary knowledge measure for assessing reading performance. Language Testing, 21, 2852.

Ricketts, J., Nation, K., \& Bishop, D. V. M. (2007). Vocabulary is important for some, but not all reading skills. Scientific Studies of Reading, 11, 235257.

Roh, S. G. (2014). A study on selecting and teaching methodologies of neologism in Korean language education (Master's thesis). Yonsei University, Seoul, Korea.

Roman, A. A., Kirby, J. R., Parrila, R. K., Wade-Woolley, L., \& Deacon, S. H. (2009). Toward a comprehensive view of the skills involved in word reading in Grades 4, 6, and 8. Journal of Experimental Child Psychology, 102, 96-113.

Schmitt, N. (2014). Size and depth of vocabulary knowledge: what the research shows. Language Learning, 64, 913-951.

Shin, M. J., \& Lee, H. R. (2016). Flexible word definition of school-aged children with specific language impairment. Communication Sciences and Disorders, 21, 111-120.

Yovanoff, P., Duesbery, L., Alonzo, J., \& Tindal, G. (2005). Grade-level invariance of a theoretical causal structure predicting reading comprehension with vocabulary and oral reading fluency. Educational measurement: Issues and Practice, 24, 4-12.

Zoh, M. H., Lee, J. M., Kim, J. O., Shin, H. J., Lee, K. O., Do, K. S., ... \& Jung, H.S. (2003). Psychology of language. Seoul: Hakjisa. 
Appendix 1. 조건별 관형구와 표적단어 예시

\begin{tabular}{lcc}
\hline 조건 & 관형구 & 표적단어 \\
\hline 우세 & 별이 빛나는 밤 & 밤공기 \\
열세 & 삶아서 먹는 밤 & 밤나무 \\
우세 & 초원을 달리는 말 & 얼룩말 \\
열세 & 친구가 하는 말 & 반대말 \\
채움 & 새벽에 울리는 종 & 종아리 \\
& 바삭하게 부친 전 & 사전 \\
\hline
\end{tabular}




\section{국문초록}

\section{초등학교 3-4학년 읽기이해부진아동의 합성어 의미 처리 특성}

심 지 ${ }^{1}$ 이은주 ${ }^{2}$

1단국대학교 대학원 언어병리학과, ${ }^{2}$ 단국대학교 특수교육과

배경 및 목적: 학령기 어휘에서 높은 비율을 차지하는 합성어는 형태소의 의미적인 결합으로 이루어지므로 합성어 이해를 위해 형태 소의 의미를 이해하여야 한다. 본 연구는 읽기이해부진아동의 합성어 의미 처리 특성을 형태소 의미의 우세와 열세 조건에 따라 살펴보 고자 하였다. 방법: 본 연구는 초등학교 3-4학년 읽기이해부진아동 11 명과 일반아동 11 명을 대상으로 하였다. 관형구의 마지막에 위치 한 동음이의어의 의미가 이후에 제시되는 합성어에 포함된 동음이의어의 의미와 관련이 있는지 여부를 판단하는 의미 관련성 판단 과 제를 사용하였다. 이때 관형구 이후에 제시되는 합성어는 우세의미 조건과 열세의미 조건으로 나뉘며 각각의 조건에 대한 정반응수와 반응시간을 측정하였다. 결과: 읽기이해부진아동이 일반아동에 비해 우세/열세의미 조건에서 모두 저조한 수행을 보였고, 의미판단시 간도 더 소요된 것으로 나타났다. 논의 및 결론: 읽기이해부진아동은 일반아동과 달리 복잡한 다형태소로 이루어진 합성어의 의미를 이해하고 처리하는 능력에서 어려움을 보였다. 읽기이해부진아동의 합성어 의미 처리와 관련하여 어휘지식, 단어의미처리속도에 대하 여 논의하였다.

핵심어: 읽기이해부진아동, 합성어, 의미 관련성 판단 과제

본 논문은 제 1 저자의 석사학위논문을수정·보완하였음.

\section{참고문헌}

강범모(2010). 언어: 풀어쓴 언어학 개론(3판). 서울: 한국문화사.

강희정, 황민아, 임종아(2013). 읽기이해부진아동의 동음이의어 이해. 학습장애연구, 10, 161-176.

고선희, 최경순, 황민아(2010). 읽기이해부진아동의 다의어 의미 처리 특성. 언어청각장애연구, 15, 348-356.

곽금주, 박혜원, 김청택(2001). 한국판 웩슬러 아동용 지능검사(K-WISC-III). 서울: 도서출판특수교육.

곽아람(2016). 읽기장애 아동과 일반 아동의 형태소인식능력과 암묵적 학습능력. 이화여자대학교 대학원 석사학위논문.

곽재용(2004). 초등학교 국어교과서의 어휘 분석. 우리말글, 32, 1-28.

김광해(2003). 등급별 국어 교육용 어휘. 서울: 박이정.

김동일, 이일화(2010). 읽기 저성취초등학생의 언어 지식과 독해력과의 관계. 학습장애연구, 7, 27-45.

김병준, 황민아, 최경순(2013). 읽기이해부진아동의 단어유추를 통한 단어처리 특성. 언어청각장애연구, 18, 269-276.

김순호, 정경희(2015). 초등 저학년 읽기학습부진아동의 형태소인식과 읽기능력. 언어치료연구, 24, 35-47.

김애화(2013). 초등학교 읽기장애학생과 일반학생의 어휘 특성 및 오류 유형 비교 연구. 학습장애연구, 10,51-67.

김애화, 유현실, 황민아, 김의정, 고성룡(2010). 초등학생의 읽기이해 능력 예측변인에 관한 연구. 언어청각장애연구, 15, 357-380.

김애화, 황민아(2008). 초등학교 고학년의 읽기능력에 영향을 미치는 읽기관련변인에 관한 연구. 언어청각장애연구, 13, 1-25.

김일병(2000). 국어 합성어 연구. 서울: 역락.

노슬기(2014). 한국어 교육용 신어 선정 및 교육 방안 연구. 연세대학교 대학원 석사학위논문.

박경숙, 김계옥, 송영준, 정동영, 정인숙(2008). 기초학력검사(Korea Institute for Special Education-Basic Academic Achievement Test, KISE-

BAAT). 안산: 국립특수교육원.

박소영(2015). 읽기이해부진아동과 일반아동의 동음이의어 이해 능력. 단국대학교 대학원 석사학위논문.

박순길, 조증열, 유영미(2013). 읽기부진아동의 문식성 예언변인 연구. 특수교육, 12, 155-180. 
박영민, 유제분(2009). 패턴시쓰기를 활용한 어휘지도 방안. 교과교육학연구, 13, 299-321.

신문자, 이희란(2016). 학령기 단순언어장애 아동의 동음이의어 정의하기. 언어청각장애연구, 21, 111-120.

이승복, 이희란(2006). 단순언어장애아동의 어휘적 모호성 이해. 언어청각장애연구, 11, 14-29.

이승복, 이희란(2007). 단순언어장애아동의 단어정의하기: 정의유형 분석을 중심으로. 언어치료연구, 16, 1-18.

이희란(2012). 자폐성장애 아동의 어휘적 모호성 단어 정의하기. 자폐성장애연구, 12,21-36.

장종윤, 정미란, 황민아(2014). 초등학교 저학년 다문화가정 아동의 동음이의어 이해와 정의하기. 언어청각장애연구, 19, 71-79.

정미란(2009). 초등학교 3-6학년 읽기이해 부진학생의 단어 유추. 언어청각장애연구, 14, 275-287.

조명한, 이정모, 김정오, 신현정, 이광오, 도경수, 이양, 이현진, 김영진, 김소영, 고성룡, 정혜선(2003). 언어심리학. 서울: 학지사.

최경순, 황민아(2010). 읽기이해부진아동의 의미 처리 특성: 의미점화효과. 언어청각장애연구, 15, 168-176.

한재영, 박지영, 현윤호, 권순희, 박기영, 이선웅, 김현경(2010). 한국어 어휘 교육. 파주: 태학사.

황미향 (2016). 동음이의어 교육의 실태와 대안: 초.중학교를 중심으로. 국어교육연구, 60, 319-342. 